\title{
Development of the Ability to Unite Movements of Schoolchildren with the Help of Exercises Classics
}

\author{
Polevoy G. G. ${ }^{1,2}$ \\ ${ }^{1}$ Moscow Aviation Institute (National Research University), Moscow, Russia \\ ${ }^{2}$ Vyatka State University, Kirov, Russia
}

Received April 19, 2021; Revised May 25, 2021; Accepted July 19, 2021

\begin{abstract}
Cite This Paper in the following Citation Styles
(a): [1] Polevoy G. G. , "Development of the Ability to Unite Movements of Schoolchildren with the Help of Exercises Classics," International Journal of Human Movement and Sports Sciences, Vol. 9, No. 4, pp. 797 - 806, 2021. DOI: 10.13189/saj.2021.090426.
\end{abstract}

(b): Polevoy G. G. (2021). Development of the Ability to Unite Movements of Schoolchildren with the Help of Exercises Classics. International Journal of Human Movement and Sports Sciences, 9(4), 797 - 806. DOI: 10.13189/saj.2021.090426.

Copyright $\odot 2021$ by authors, all rights reserved. Authors agree that this article remains permanently open access under the terms of the Creative Commons Attribution License 4.0 International License

\begin{abstract}
Background: The problem of lack of physical activity of schoolchildren can be solved by supplementing the standard physical education programs at school. Material and methods: Pedagogical experiment lasted nine months, which was attended by 50 children from the second grade. Children were engaged in physical culture at school twice a week for 40 minutes each lesson. General coordination abilities were determined by the test «Shuttle run $3 \times 10 \mathrm{~m}$ », and the ability to unite the movements of schoolchildren were determined by the test «Jumping on the spot». Statistical and mathematical analysis of the results was carried out using Microsoft Excel 2016 and Bio-Statistica 2009. The study used the parametric criterion T-Student. The result was significant at $\mathrm{P}<0.05$. Results: After the pedagogical experiment, the indices in children in CG in both tests improved, but not significantly. In the EG, the children which were engaged in the standard program, but additionally performed the exercise «Classic's» at each lesson of physical culture in school, which significantly improved the general coordination abilities in the test «Shuttle run» from $10.5 \pm 0.8 \mathrm{sec}$ to $8.5 \pm 0.5 \mathrm{sec}(\mathrm{P}<0.05)$ and indicators in the test «Jumping on the spot» by $34.9 \%(\mathrm{P}<0.05)$. Conclusion: If the lessons of physical education in school with children 8-9 years to perform additional exercise «Classic's», the indicators of their coordination abilities and ability to unite movements will improve significantly.
\end{abstract}

Keywords Coordination Ability Unite Movements, Schoolchildren, Physical Culture Lesson

\section{Introduction}

Lack of physical activity of children in primary school age is an urgent problem today, every year younger and progressive disease of varying severity. Physical training and exercise, in general, contribute to the strengthening of the body. Lesson in physical culture at school, is the main and mandatory form of organization of classes for schoolchildren. At the physical education lesson at the school, which takes place twice a week for 40 minutes, schoolchildren should receive comprehensive training and training in new movements $[1,2]$.

Comprehensive harmonious development of schoolchildren, training and education, increasing interest and motivation for further physical education - these are the basic principles that are laid down in the standard program for physical education in school [3]. The problem that exists in many schools in the region is the lack of space for physical education. If there are gyms, they are very small. The teacher must show his creative skills to meet the 40 minutes and give the necessary motor activity to each schoolchild. The solution to this problem is possible in the development and implementation of the process of physical education in the school of new physical exercise, which does not require significant financial costs, special physical and mental skills to perform it. One of such exercises is «Classic's». 
In addition, a great importance in the development of children plays a sufficient level of physical abilities, such as strength, speed and others.

Strength - the ability of a person to overcome external resistance or counteract it with the help of muscle tension.

Speed is the ability of a person to perform motor actions in the minimum period of time for these conditions.

Endurance - the ability of a person to resist fatigue.

Flexibility - the ability of a person to perform movements with a large amplitude.

One of the most important abilities in primary school age is coordination ability. A schoolchild who has high rates of coordination abilities is able to quickly and accurately solve motor problems that arise suddenly [4-6].

Factors that determine the manifestation of coordination abilities:

1. The ability of a person to a precise analysis of movements

2. The activity of the analyzers (especially motor)

3. The complexity of the motor task

4. Level of development of other physical qualities

5. The level of General preparedness working (volume school movements)

6. Depends on the age

7. Courage and determination

The basic means of physical exercise of high coordination complexity contains elements of novelty.

Today there are several classifications of coordination abilities. The main types are general, special and specific coordination abilities $[7,8]$.

General coordination abilities are the potential and realized capabilities of a person that determine their readiness for optimal management of various motor actions of origin and meaning.

Special ones belong to groups of motor actions that are homogeneous in terms of psychophysical mechanisms and are systematized according to increasing complexity. In this regard, special coordination abilities differ:

- in all sorts of cyclical (walking, running, crawling, climbing, climbing, swimming, locomotion (moving) on devices - skates, bicycles, rowing, etc.) and acyclic motor actions (jumping);

- in non-motor movements of the body in space (gymnastic and acrobatic exercises);

- in the movements of manipulating individual parts of the body in space (pointing, touching, pricking, contour tracing, etc.);

- in movements of moving things in space (shifting objects, winding a cord on a stick, lifting weights);

- in ballistic (throwing) motor actions with a setting for the range and strength of throwing (shot put, throwing a grenade, disc, hammer);

- in throwing movements for accuracy (throwing or throwing various objects at the target, tennis, towns, juggling);

- in aiming movements; in imitative and copying movements;

in attacking and defensive motor actions of martial arts (wrestling, Boxing, fencing, martial arts);

- in offensive and defensive technical and technical-tactical actions of mobile and sports games (basketball, volleyball, football, hand ball, ice hockey, etc.).

The above systematization does not include a number of groups of coordination abilities that relate to labor actions and household operations.

Along with special coordination abilities, we should distinguish the so-called specific or special (horizontal classification of coordination abilities). The most important of them include: the ability to orientate in space, balance, rhythm; the ability to reproduce, differentiate, evaluate and measure the spatial, temporal and power parameters of movements; the ability to react, the speed of motor activity rearrangement; the ability to coordinate movements, arbitrary muscle tension and statokinetic stability. Let's give a brief definition of these abilities.

The ability to orientate is understood as the ability of an individual to accurately determine and promptly change the position of their body and make movements in the right direction. The ability to differentiate movement parameters determines the high accuracy and economy of spatial angles (positions of angles in the joints), power (state of tension in the working muscles) and temporary (high sense of microintervals of time) movement parameters. Responsiveness allows you to quickly and clearly perform a whole, short-term movement to a known or unknown signal in advance with the whole body or part of it (arm, leg, trunk). The ability to rearrange motor actions is the speed of transformation of developed forms of movements or switching from one motor action to another, according to changing conditions. The ability to negotiate the Union is the subordination of the individual movements and actions in a complete motor combination. The ability of balance is the ability to maintain the stability of the pose (balance) in certain static positions of the body (in stands), in the course of performing movements (in walking, during acrobatic exercises, in the fight with a partner). The ability of rhythm is the ability to accurately reproduce a given rhythm of motor action or adequately vary it in connection with changed conditions. Vestibular (statokinetic) stability is the ability to accurately and stably perform motor actions in the conditions of vestibular stimuli (somersaults, throws, turns, etc.). Voluntary muscle relaxation is the ability to optimally coordinate the relaxation and contraction of certain muscles at the right time.

Among the specific coordination abilities, the ability of children to unite movements should be particularly highlighted. It is the ability to combine separate movements and actions in a complete motor combination [9]. The earlier children master the majority of coordination abilities and the higher the level of their 
development, the easier it will be to perform motor tasks, the better the technique of any physical exercise, the higher the results in sports $[10,11]$.

At this age, the anatomical and physiological maturation of the systems that provide motor activity of the child is completed. However, at the beginning of the period, these systems are still far from maturing, the process of motor development itself is still far from complete, although it occurs at this age with a high degree of intensity.

Primary school age is characterized by a relatively uniform development of the musculoskeletal system, but the intensity of growth of individual dimensional signs of it is different. Thus, the length of the body increases during this period to a greater extent than its mass.

The joints of children of this age are very mobile, the ligamentous apparatus is elastic, and the skeleton contains a large amount of cartilage tissue. The vertebral column retains great mobility up to 8-9 years. Research shows that primary school age is the most favorable for directed growth of mobility in all major joints.

The muscles of children of primary school age have thin fibers, contain only a small amount of protein and fat. At the same time, large limb muscles are more developed than small ones.

At this age, the morphological development of the nervous system almost completely ends, and the growth and structural differentiation of nerve cells ends. However, the functioning of the nervous system is characterized by a predominance of arousal processes.

In primary school age, almost all indicators of physical qualities show very high growth rates. The only exception is the indicator of flexibility, which growth rates begin to decrease during this period.

At the age of 7-10 years, there is also a rapid development of the biodynamics of the child's movements, and above all their coordination component.

Thus, the age range of 7-10 years is most favorable for the development of almost all motor and coordination abilities realized in human motor activity.

For the practice of physical education, indicators of the functional capabilities of the child's body are the leading criteria for choosing physical activity, the structure of motor actions, and methods of influencing the body.

For children of primary school age, the need for high motor activity is natural. Motor activity is understood as the total number of motor actions performed by a person in the course of everyday life. When free mode in the summer, children aged 7-10 years old make 12 to 16 thousand movements per day.

Psychological characteristics of primary school children are as follows.

The ability to perceive and observe external reality in children of primary school age is still imperfect: children perceive external objects and phenomena inaccurately, highlighting in them random signs and features that for some reason attracted their attention.

A feature of the attention of schoolchildren is its involuntary nature: it is easily and quickly distracted by any external stimulus that interferes with the learning process. The ability to concentrate on the phenomenon under study is also not sufficiently developed. They can't keep their attention on the same object for a long time. Intense and focused attention quickly leads to fatigue.

Memory in primary school children has a visual and figurative character: children remember the external features of the studied subjects better than their logical semantic essence. Children of this age still find it difficult to connect in their memory the individual parts of the phenomenon being studied, it is difficult to imagine the overall structure of the phenomenon, its integrity and the relationship of parts. Memorization is mostly mechanical, based on the strength of the impression or on repeated repetition of the act of perception. In this regard, the process of reproduction, learned from schoolchildren, is inaccurate, a large number of errors, memorized is not long held in memory.

All of these has a direct bearing on learning movements in physical education. Numerous observations show that schoolchildren forget much that they learned 1-2 months ago. To avoid this, it is necessary to repeat the training material with children systematically over a long period of time.

Thinking in children at this age also differs visually-imaginative character, inseparable from the perception of specific features of the studied phenomena, closely related to the activity of the imagination. Children still have difficulty learning concepts that are highly abstract, since they are not related to concrete reality except for verbal expression. And the reason for this, mainly, is the lack of knowledge about the General laws of nature and society.

That is why at this age, techniques of verbal explanation are ineffective, separated from visual images of the essence of phenomena and its determining laws. Visual learning is the main method of learning at this age. The movement display should be simple in its content. It is necessary to clearly identify the necessary parts and main elements of movements, to fix the perception with the help of words. At the same time, it should be borne in mind that schoolchildren perceive rhythmic, power and spatial images of movements primarily in sensations and generalizations of impressions, and to a lesser extent through awareness, thoughtful development of technical action. Therefore, learning a complete exercise will be more successful at this age than learning it in detail. Children of this age are almost independent. Only after watching how it is done can they master the movement of skis, skates, learn to communicate with the ball, show sports and game savvy.

Of great importance for the development of the function of thinking are games that require the manifestation of 
strength, dexterity, speed, the movements themselves, and response to various circumstances and situations of the game. The educational value of outdoor games is great: in the process of playing activities, literally all the mental functions and qualities of the child develop: acuteness of sensations and perception, attention, memory, imagination, thinking, social feelings, and volitional qualities.

However, this positive influence is achieved only with proper pedagogical guidance of games. Outdoor games are also useful for developing the ability of schoolchildren to regulate their emotional States. Interest in games is associated with bright emotional experiences in children. They are characterized by the following features of emotions: direct character, bright external expression in facial expressions, movements, exclamations. Children of this age are not yet able to hide their emotional State. They spontaneously succumb to them. The Emotional state changes rapidly in both intensity and character. Children are not able to control and restrain emotions if the circumstances require it. These qualities of emotional States presented to the spontaneous flow can be fixed and become character traits. In primary school age, strong-willed qualities are formed and brought up. As a rule, they are guided only by their immediate goals in their volitional activity. They cannot yet put forward long-term goals that require intermediate actions to achieve them. But even in this case, children of this age often do not have the endurance, the ability to persevere, the required result. Some of their goals are quickly replaced by others. Therefore, it is necessary to educate children with a stable sense of purpose, self-control, initiative, independence, and determination.

Unstable and character traits of the younger schoolboy are as follows. This is especially true for the moral traits of the child's personality. Often children are capricious, selfish, rude, and undisciplined. These undesirable manifestations of the child's personality are associated with improper preschool education.

The specificity of physical exercises opens up great opportunities for the education and development of children's necessary strong-willed qualities.

After getting acquainted with the anatomical, physiological and psychological features, it is necessary to pay attention to the correct organization and construction of additional physical exercises with children of primary school age. Exercises should be given taking into account the physical fitness of schoolchildren. The load should not be excessive. Classes are held no more than 1-2 times a week, taking into account the fact that the children are engaged in physical education lessons 2 times. Training should be visual in nature with a simple and clear explanation.

You need to pay special attention to the formation of correct posture in children and teaching proper breathing when performing physical exercises. In the classroom, outdoor games are widely used as an indispensable educational tool for the development of moral, volitional and physical qualities of a schoolchild.

Features of methods of physical education are as follows.

The beginning of the school period is associated with a very burdensome element of the school regime, long sitting at a Desk, which contributes to chronic overload of the spine. This should be taken into account when selecting exercises for physical education. It is advisable to use bending, deflection, and rotation.

At the age of 6-7, the reserve capabilities of the cardiovascular and respiratory systems, which allow performing moderate-intensity aerobic work for a long time, significantly increase in comparison with children of 4-5 years. Many studies have shown that it is possible to develop endurance in 6-7 - year-old children by widely including in physical culture lessons classes of cyclically repeated sets of physical exercises, even running, walking on skis, Cycling and other exercises of a cyclical nature. It is necessary to stimulate the development of endurance, since it is closely related to the child's performance and determines his readiness to study at school, at school, contributes to the successful overcoming of educational loads, better assimilation of knowledge in General subjects.

Moderate intensity loads (40-60\% of the maximum) contribute to improving the functional capabilities of the body, reducing the incidence of diseases. The volume of even running for 6-year-old children can be 1000-1500 or more.

The ability of children to perform low-intensity work for a relatively long time increases. Especially high sensitivity to the effects of low-intensity exercises that develop endurance in children aged 11 years. From 12 to 15 years of age, the effectiveness of these exercises decreases, endurance is stabilized or even slightly reduced.

Primary school age is the most important period in the formation of motor coordination of the child. At this age, the foundations of movement culture are laid, new, previously unknown exercises and actions, physical culture knowledge are successfully mastered.

Changes in the mode of life associated with the beginning of school, as well as the incomplete process of forming the motor apparatus, make it necessary to exercise caution when dosing physical loads of schoolchildren. Restrictions apply to the use of strength exercises, endurance training loads, and the time of individual classes.

During this period, there is a formation of individual interests and motivations for physical exercise, including sports.

In early school age, it is necessary to develop the child's interest in expanding the range of physical abilities by mastering the basics of sports exercises, techniques and actions. The development of motor coordination is the 
main focus of physical training of primary school children. By the end of the period, it is advisable to Orient the child to engage in the sport or physical activity that best corresponds to his abilities and interests and can be implemented in the specific conditions of life of this child.

Children's ability to learn movement techniques is so great that many new motor skills are acquired without special instruction. Studies on the features of teaching children of primary school age have shown that they are much faster to master the basic elements of sports exercise techniques than teenagers and young men. At the same time, it was found that children perceive the rhythmic and forceful image of movement primarily in sensations and generalized impressions, and to a lesser extent - by "conscious", thoughtful mastering of the details of the technique. This phenomenon seems to explain the fact that learning a complete exercise at this age is more successful than learning it by elements. That is why children who are almost independent, only after observing "how it is done", can master movement on skis, skates, bicycles, demonstrate the ability to handle a ball, a racket, show sports and playing abilities.

The most appropriate age related features of the development of human motor potential during this period of life will be the training regime of the child aimed at providing General physical training with an accentuated increase in coordination abilities.

At the age of $7-10$ years, interests and propensities for certain types of physical activity begin to form. The specificity of individual motor manifestations and predisposition to certain types of sports is revealed. This creates the conditions for successful physical education and sports orientation of schoolchildren to determine the optimal path of physical improvement for each of them.

Purposefully develop general and specific coordination abilities better in primary school age. A favorable period for the development of coordination abilities of children is the age of $7-10$ years $[12,13]$.

The hypothesis of the study is that if schoolchildren 8-9 years old at each lesson of physical culture will perform the exercise «Classic's», their performance of general coordination abilities and ability to unite movements will improve significantly.
Thus, the aim of the study is to study the impact of the exercise «Classic's» on the performance of general coordination abilities and the ability to unite the movements of younger schoolchildren.

\section{Materials and Methods}

During the school year, a pedagogical experiment was conducted (September-May), which lasted nine months. It was attended by 50 children, boys and girls from the second grade of school №60, Kirov, Russia. At the time of the study, the children were 8-9 years old. All children were admitted to practical lessons on physical culture at school, which were held by the teacher twice a week for 40 minutes each lesson.

Before the start of the study were formed two groups: Control group (CG) 25 children, which are the schoolchildren of $2 \mathrm{~A}$ class. They were engaged in standard physical education at school [3]. The experimental group (EG) consists of 25 schoolchildren from $2 \mathrm{~B}$ class. They were engaged in the standard program, but at each lesson in physical culture additionally performed the exercise «Classic's» (table 1).

In the gym on the floor there are three large square (a square of side equal to $180 \mathrm{~cm}$ ). Inside each large square there are nine small squares, they have numbers from 1 to 9. Each schoolchild must jump in one large square from 1 to 9 , then in the opposite direction, from 9 to 1 . After that, it can move to the second large square in which the numbers are arranged in a different order. Before each class numbers in the squares have changed. Square-to-square jump can be any. In case of an error, the schoolchild returns to the square with the previous number.

Tests:

1) The Level of development of general coordination abilities was determined by the test «Shuttle run $3 \times 10$ m» [14];

2) The Level of development of the ability to unite the movements of the schoolchildren was determined on the test «Jumping on the spot» [15].

Table 1. Exercise «Classic's»

\begin{tabular}{|c|c|c|c|c|c|c|c|c|}
\hline 8 & 6 & 2 & 3 & 6 & 5 & 9 & 6 & 3 \\
\hline 5 & 3 & 7 & 2 & 8 & 7 & 1 & 7 & 8 \\
\hline 9 & 4 & 1 & 9 & 1 & 4 & 2 & 5 & 4 \\
\hline \multicolumn{3}{|c|}{ Square 1} & \multicolumn{3}{|c|}{ Square 2} & \multicolumn{3}{|c|}{ Square 3} \\
\hline
\end{tabular}


The starting position (SP) - its feet together, arms along the body.

1. Legs apart, arms along the torso;

2. SP;

3. Legs apart, arms apart;

4. SP.

If the schoolchild made a mistake, he returns to the SP and continues to perform the exercise. The result is a consistent number of SP in 30 seconds.

\section{Statistical Analysis}

During the pedagogical research, Microsoft excel 2016 and biostat 2009 programs were used. Statistical processing of the results was performed using the biostat 2009 program, wherein the parametric t-student criterion and the reliability of the results was considered at $\mathrm{P}<0.05$. In mathematical processing, the average value of indicators in groups was determined using Microsoft excel $2016[16,17]$.

\section{Results}

Before the study, all schoolchildren passed two control tests. Results between schoolchildren $2 \mathrm{~A}$ and $2 \mathrm{~B}$ class were not significant. After the pedagogical experiment, all schoolchildren again passed control tests (table 2).

Table 2 shows that the performance in both tests improved for all schoolchildren. Children from class 2A, who were engaged in the standard program and did not perform additional exercises, improved general coordination abilities in the test «Shuttle run» by $3.9 \%$, and in the test «Jumping on the spot» performance improved from $12.1 \pm 1.6$ to $13.7 \pm 1.3 \quad(\mathrm{P}<0.05)$. These results may indicate the effectiveness of the use of a standard program for physical education in school lessons with younger schoolchildren.

In the EG, in which children from $2 \mathrm{~B}$ class were engaged in the standard program, but additionally performed the exercise «Classic's» at each lesson of physical culture in school, significantly improved the general coordination abilities in the test «Shuttle run» from $10.5 \pm 0.8 \mathrm{sec}$ to $8.5 \pm 0.5 \mathrm{sec}(\mathrm{P}<0.05)$ and indicators in the test «Jumping on the spot» by $34.9 \%(\mathrm{P}<0.05)$. These results indicate the effectiveness of the use of exercises «Classic's» in the classroom with children of primary school age.

\section{Discussion}

Human health is influenced by the following factors: the environment (geography, climate, ecology) - 20\%, the health system (lack of constant medical control, low level of primary prevention, poor quality medical care) $-10 \%$, genetics-20\%, and lifestyle (daily routine, personal hygiene, body hardening, nutrition, motor activity) $-50 \%$.

Lifestyle plays a significant role in maintaining human health.

One of the components of a lifestyle is motor activity.

Motor activity has always been the most important link in the adaptation of living organisms to the environment and in the course of evolution it has formed as a biological need of man on a par with the needs for food, water, self-preservation, and reproduction.

The importance of motor activity in the life of modern man has been confirmed by many studies.

Physiologists consider movement to be an innate vital need of a person. Full satisfaction of the need for movement, in their opinion, is especially important in preschool and primary school age, when the main systems and functions of the body are formed.

Doctors say that without movement, the child cannot grow up healthy.

According to psychologists, personal development is carried out in activities. The first ideas about the world, its objects and phenomena come to the child through movements.

Many well-known teachers note that movement is an important means of not only development, but also education of the child, contributing to the formation of his personality.

Table 2. The indicators of general and kinesthetic coordination abilities of football players of 8-9 years $(\mathrm{M} \pm \mathrm{m})$

\begin{tabular}{ccccccccc}
\hline \multirow{2}{*}{ Test } & \multicolumn{4}{c}{ CG } & \multicolumn{3}{c}{ EG } \\
\cline { 2 - 8 } & Before & After & $\%$ & P & Before & After & $\%$ & P \\
\hline Shuttle run 3x10 m (s) & $10.1 \pm 0.9$ & $9.7 \pm 0.5$ & 3.9 & $\mathrm{P}<0.05$ & $10.5 \pm 0.8$ & $8.5 \pm 0.5$ & 19.1 & $\mathbf{P}<\mathbf{0 . 0 5}$ \\
\hline $\begin{array}{c}\text { Jumping on the spot } \\
\text { (number of SP) }\end{array}$ & $12.1 \pm 1.6$ & $13.7 \pm 1.3$ & 13.2 & $\mathrm{P}<0.05$ & $12.9 \pm 1.6$ & $17.4 \pm 1.5$ & 34.9 & $\mathbf{P}<\mathbf{0 . 0 5}$ \\
\hline
\end{tabular}


However, in recent decades, both adults and children have been observed insufficient in physical activity, which causes the appearance of hypokinesia and a number of serious changes in the human body.

Data from long-term observations revealed low motor activity of schoolchildren in General education institutions, which, depending on age, ranges from $25-60 \%$ of the required time of special motor activity.

The health-improving effect of school children from motor activity primarily depends on its daily total value, i.e., on the organization of not only physical education, but also the entire educational process, as well as the organization of free time by the schoolchildren. Nevertheless, an important place in health promotion is given to increase motor activity by means of school physical education.

A physical education lesson is the only subject in the school curriculum and the only means in the school physical education system that could better satisfy the child's biological need for movement.

However, the modern lesson physical culture looks like something quite insignificant, secondary among all other forms of physical education, which leads to doubts about whether it is the main, irreplaceable form of physical education of schoolchildren.

The teacher's underestimation of individual morph functional features of schoolchildren, especially in primary school age, and the lack of motivation for active physical activities negatively affect the child's attendance at the physical culture lesson (with the support of parents, of course), on the child's activity at the physical culture lesson. In addition, the imperfection of the fixed form of physical education classes is one of the main reasons for the low effectiveness of the physical education lesson.

There is a need to develop and implement new, more progressive forms of increasing motor activity in the organization of the educational process and identify effective tools and methods that allow for the intensification of physical education lessons in conditions of time deficit. This process requires a deeper study of motor activity.

Recently, publications and the press have published a lot of works devoted to the study of the problem of motor activity of children. However, the relationship of motor activity with the organization of school physical education, in particular, the lesson physical culture is presented superficially. You can find a variety of recommendations about the construction of the lesson and the interpretation of the method of teaching physical exercises, etc. Basically, these are theoretical calculations that do not have references to practice.

The problem of lack of motor activity of children of primary school age is relevant, especially in recent years $[1,2,18]$. Some authors propose to create a new curriculum for physical education, some are talking about introduction of extra classes or clubs for schoolchildren
[19-21]. In our opinion, this approach is not quite correct. Changing the physical education program at school is wrong. The standard program on physical culture at school allows to cover all range of abilities and skills of schoolchildren, their physical and mental development. The standard program not only disciplines and teaches, but also comprehensively develops schoolchildren physically and psychologically. The effectiveness of the standard program of physical culture at school is proved by this study. The performance of schoolchildren who took part in the pedagogical experiment, all without exception, including those who did not perform additional exercises, improved on all tests that were in the study.

The study confirms the fact that the favorable period for the development of general coordination abilities and the ability of schoolchildren to unite movements is the primary school age. The natural increase of indicators affected, as the indicators of children not only in EG, but also in CG improved [7, 8, 22].

The efficiency performance of exercise «Classic's» on the lessons of physical culture in the school, was fully proved by the present study. Children who performed the exercise «Classic's», significantly improved their performance coordination abilities and abilities to unite movements.

The uniqueness of the exercise «Classic's» is the simplicity of its implementation. It does not require significant material investments, complex equipment and special training. It can be done in any part of the lesson.

One of the important indicators of the teacher's work at school, especially in physical education lessons, is the emotional background and mood of schoolchildren for the lesson. Pedagogical observation of the process of physical education of schoolchildren, of course, shows that emotionally, children from the experimental group were set up much better than the schoolchildren who were engaged in the standard program. Game and competitive component in working with younger schoolchildren is very important [23]. In the classroom, children tried to speed up the exercise «Classic's», overtaking each other.

In addition, in working with children it is very important to use a differentiated approach, which allows you to dose the load for each schoolchild [24-25]. The schoolchildren choose the place and time for jumping during the lesson of physical culture, the speed of moving through the squares, the height and duration of jumps, and some other aspects of the load. It depends on schoolchildren's well-being and desire for self-development and self-preparation. The topic is relevant and is a continuation of some research [26-27].

\section{Conclusions}

Tasks there are solved at primary school age include: 
1) health promotion, improved posture, prevention of flat feet, promotion of harmonious physical development, development of resistance to adverse environmental conditions;

2) mastering the basics of various vital movements;

3) development of coordination (accuracy of reproduction and differentiation of spatial, temporal and power parameters of movements, balance, rhythm, speed and accuracy of response to signals, coordination of movements, orientation in space) and conditioning (speed, speed-power, endurance and flexibility) abilities;

4) formation of basic knowledge about personal hygiene, daily routine, the impact of physical exercise on health, performance and development of motor abilities;

5) develop ideas about the main sports, about the equipment and equipment used in them, and about compliance with safety rules during training;

6) introduction to independent physical exercises, outdoor games, use them in their free time on the basis of forming interests in certain types of motor activity and identifying predisposition to certain sports;

7) education of discipline, friendly attitude to friends, honesty, responsiveness, courage during physical exercises; assistance in the development of mental processes (representation, memory, thinking, etc.) in the course of motor activity.

It is proved that the exercise «Classic's» significantly improves the general coordination abilities and ability of children to unite movements, which is an excellent addition to the standard program of physical culture in school, especially in working with children of primary school age. The results of the study are relevant for teachers and promising for the improvement of modern programs of physical culture in school.

\section{Recommendations for Conducting a Physical Culture Lesson}

Physical exercises in primary school are mainly done in physical education lesson, which is built in accordance with the General pedagogical provisions, as well as with the methodological rules of physical education. The specificity of the tasks and content of the physical education program determines some features of the physical education lesson, taking into account the age characteristics of schoolchildren.

1. For primary school age, the leading tasks in the lesson are to improve natural motor actions (walking, running, jumping, throwing, climbing, etc.).

2. In one lesson, it is advisable to solve no more than 2-3 tasks related to the assimilation or improvement of educational material.
3. In the younger the class, more attention is paid to strengthening the foot muscles and forming correct posture.

4. Each lesson must we play active games. Game material can take up about half of the total time of classes with children under the age of 10-11 years.

5. When teaching schoolchildren, the main types of movements, great attention should be paid to the correctness and accuracy of performing exercises (school of movements), as well as to combine the learning process with the development of motor abilities.

From the methods of the exercise, the advantage is given to the holistic method. The split method has an auxiliary value.

When explaining a motor task, it is necessary that children correctly understand what to do and how to do it. Therefore, it is recommended that the motor task be set in a specific form: for example, to catch, catch up, get into the ring, etc.

For children of primary school age, if possible, it is necessary to exclude significant static stresses and exercises associated with straining (breath retention).

One of the ways to activate motor actions of primary school children is to perform various exercises (movements) for didactic stories. The teacher tells a story, and the schoolchildren accompany his story with appropriate movements, trying to creatively reproduce all the situations in action. It is desirable that these stories have a thematic (plot) character and have a poetic form.

In this case, physical exercise takes the form of a game.

Physical activity of schoolchildren is held in the form of organized classes in the framework of school physical education. Physical education and recreation classes can be supplemented with daily morning exercise and two or three training sessions per week. If the child is engaged in the sports section, then home classes may be limited to weekends.

Qualitative indicators of the level of physical culture of a primary school child:

1. Knowledge of the basic rules of conducting an independent training session, techniques for elementary control of your physical condition, dosage, content and purpose of the simplest hardening procedures.

2. The ability to independently conduct morning exercises, physical training, and individual training sessions.

3. The ability to organize a sports or outdoor game with peers.

4. Knowledge of the basics of techniques and tactics of various physical exercises, techniques and actions.

5. Versatile physical fitness at the level of age standards of the curriculum. 
6. Systematic conduct of morning gymnastics, participation in joint training sessions, regular independent classes on the instructions of a coach or physical education teacher.

7. Constant interest in improving the level of their physical fitness and hardening the body.

8. Knowledge of interesting facts from the history of sports and examples of achievements in improving people's health by means of physical culture and sports.

9. Knowledge of current sports events in the city, country, and abroad.

\section{REFERENCES}

[1] Donnelly, J., Hillman, C., Castelli, D., Etnier, J., Lee, S., Tomporowski, P., Lambourne, K., Szabo-Reed, A. Physical Activity, Fitness, Cognitive Function, and Academic Achievement in Children: A Systematic Review. Medicine and science in sports and exercise 2016; 48(6):1197-1222. doi:10.1249/MSS.0000000000000901.

[2] Shuba L.V. Modern approach to implementation of health related technology for primary school children. Pedagogics, psychology, medical-biological problems of physical

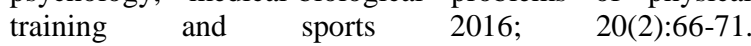
https://doi.org/10.15561/18189172.2016.0210

[3] Lyakh VI, Zdanevich AA. Work program on physical culture, grade 1-4. Moscow: Education 2010; 80 p.

[4] Čillík I, Willwéber T. Influence of an exercise programme on level of coordination in children aged 6 to 7 . Journal of Human Sport and Exercise 2018; 13(2):455-465. doi:10.14198/jhse.2018.132.14

[5] Fernandes VR, Ribeiro MLS, Melo T, Maciel-Pinheiro PdT, Guimarães TT, Araújo NB, Ribeiro S, Deslandes AS. Motor coordination correlates with academic achievement and cognitive function in children. Frontiers in Psychology 2016; 7:318. doi: 10.3389/fpsyg.2016.00318

[6] Jaakkola J, Watt A, Kalaja S. Differences in the Motor Coordination Abilities Among Adolescent Gymnasts, Swimmers, and Ice Hockey Players. Human Movement 2017; 18(1): 44-49. DOI: https://doi.org/10.1515/humo-20 $17-0006$

[7] Alexandrova VA, Shian VV. Some types of the coordination abilities of the athlete-dancers. Uchenye zapiski universiteta imeni P.F. Lesgafta 2014; 112(6):12-17. https://doi.org/10.5930/issn.1994-4683.2014.06.112.p12-1 7.

[8] Hirtz P. Koordinative Fahigkeiten Im Schulsport, Berlin: Volk und Wissen, Volkseigener. 1985.

[9] Polevoy GG. The development of speed-power qualities of schoolchildren with different typologies applying coordination training. Pedagogics, Psychology, Medical-Biological Problems of Physical Training and Sports 2019; 23(1):43-46. https://doi.org/10.15561/181891 72.2019 .0107
[10] Shawkat R. The impact of development of the special coordination abilities on the general skill ability for table tennis juniors under 12 years old. International journal of science culture and sport 2014; 2(2):30-42. https://doi.org/10.14486/ijscs71

[11] Erceg M, Zagorac N, Katić R. The impact of football training on motor development in male children. Collegium antropologicum 2010; 32(1):241-247.

[12] Larisa S. Extremely Early High Abilities, Sensitive Periods, and the Development of Giftedness: a conceptual proposition. High Ability Studies 2006; 8(2):247-258. https://doi.org/10.1080/1359813970080209

[13] Charles HZ, Megan RG, Robert BM, Jana MK, Nathan AF. Sensitive Periods. Monographs of the society for research in child development 2011; 76(4): 147-162. http://doi.org/10.1111/j.1540-5834.2011.00631.x

[14] Polevoy GG. The influence of coordination abilities on the development of the volume of dynamic attention in children with different types of nervous system. International Journal of Applied Exercise Physiology 2019; 8(1):92-97.

[15] Lyakh VI. Coordination abilities: diagnostics and development. - Moscow: TVT Division 2006; 290 p.

[16] Khusainova RM, Shilova ZV, Curteva OV. Selection of appropriate statistical methods for research results processing. Mathematics Education 2016; 11(1):303-315. doi: 10.12973/iser.2016.21030a

[17] Oldham J. Statistical tests (Part 2): parametric tests. Nursing standard 1993; 44:28-30. https://doi.org/10.7748/ns.7.44.2 $8 . s 54$

[18] François T, Roy JSh. School physical activity, school sports and academic performance. The international journal of behavioral nutrition and physical activity 2008; 5(10). https://doi.org/10.1186/1479-5868-5-10

[19] Maureen D, Heather H, Kara D, Rebecca LL. School-based physical activity programs for promoting physical activity and fitness in children and adolescents aged 6 to 18. Journal Cochrane Systematic Review 2013; 1-10. DOI:10.1002/14651858.CD007651.pub2

[20] Dallolio L, Ceciliani A, Sanna T, Garulli A. Proposal for an Enhanced Physical Education Program in the Primary School: Evaluation of Feasibility and Effectiveness in Improving Physical Skills and Fitness. Journal of physical activity \& health 2016; 13(10). DOI: 10.1123/jpah.2015-0694

[21] Gregor S, Janko S. Influence of the quality implementation of a physical education curriculum on the physical development and physical fitness of children. Journal BMC public health 2012; 12(61). https://doi.org/10.1186/1471-2 458-12-61

[22] Starosta W, Hirtz P. Sensitive and critical periods of motor coordination development and its relation to motor learning. Journal of human kinetics 2002; 7:19-28

[23] Wood C, Hall K. Physical education or playtime: Which is more effective at promoting physical activity in primary school children? BMC Research Notes 2015; 8(1):12. https://doi.org/10.1186/s13104-015-0979-1 
[24] Milić M, Grgantov Z, Chamari K, Ardigò LP, Bianco A, Padulo J. Anthropometric and physical characteristics allow differentiation of young female volleyball players according to playing position and level of expertise. Biology of Sport 2017; 34(1):19-26. https://doi.org/10.5114/biolsport.2017.63382

[25] Whipp P, Taggart A, Jackson, B. Differentiation in outcome-focused physical education: pedagogical rhetoric and reality. Journal Physical Education and Sport Pedagogy 2014; 19(4):

https://doi.org/10.1080/17408989.2012.754001
[26] Polevoy G.G. Use of Exercise Classics in Physical Education Classes for the Development of Vestibular Stability of Schoolchildren. International Journal of Human Movement and Sports Sciences, 9(2), 180-184, 2021. https://doi.org/10.13189/saj.2021.090203.

[27] Palmizal A. , Dian Pujianto , Nurkadri , Anak Agung Ngurah Putra Laksana , "Development of a Creative Gymnastics Model to Improve Basic Locomotor Movements for Students in Elementary School," International Journal of Human Movement and Sports Sciences, Vol. 8, No. 6A, pp. 78 - 84, 2020. DOI: 10.13189/saj.2020.080714. 